\title{
Down in the Wadi: the locomotory activity rhythm of the Arabian spiny mouse, Acomys dimidiatus from the Arabian Peninsula.
}

\author{
A.N. Alagaili ${ }^{1}$, O.B. Mohammed ${ }^{1}$, N.C. Bennett ${ }^{1,2}$ and M.K. Oosthuizen ${ }^{2, *}$
}

${ }^{1}$ KSU Mammals Research Chair, Department of Zoology, College of Science, King Saud University, P.O. Box 2455, Riyadh 11451, Saudi Arabia,

${ }^{2}$ SARChI Chair, Mammal Behavioural Ecology and Physiology, Department of Zoology \& Entomology, University of Pretoria, Pretoria, 0002, South Africa.

* Corresponding author
e-mail address: moosthuizen@zoology.up.ac.za

\begin{abstract}
The circadian rhythm of locomotory activity in the Arabian spiny mouse, a desert living species, was investigated under controlled laboratory conditions. Ten individuals were subjected to successive light cycles. When subjected to a 12L:12D light cycle, locomotor activity was confined mainly to the dark phase (mean $94.2 \% \pm 1.6 \%$ ). During a period of constant darkness (DD), all animals expressed free running rhythms of locomotor activity (mean $23 \mathrm{~h} 49 \pm 0 \mathrm{~h} 04$ ). Following a second LD cycle, the light and dark phases were inversed (12D:12L). Activity shifted with the lights and was masked during the light phase, reentrainment was rather slow (up to 10 days). The effect of varying ambient temperature (20 to $35^{\circ} \mathrm{C}$ ) on the locomotor activity under a $12 \mathrm{~L}: 12 \mathrm{D}$ cycle revealed that temperature had no distinct effect on the level of locomotor activity. When the dark component of the day was lengthened to $8 \mathrm{~L}: 16 \mathrm{D}$, the mean percentage of activity during the dark increased to $96.0 \pm 0.8$ $\%$, while a significant decrease in night time activity was observed when the dark phase length was decreased to $16 \mathrm{~L}: 8 \mathrm{D}(78.29 \pm 2.52 \%)$. The Arabian spiny mouse therefore behaves as other desert dwelling rodents and can be described as truly nocturnal.
\end{abstract}

Key words: circadian rhythm, light-dark cycle, locomotor activity, Saudi Arabia, Acomys, Spiny mouse 


\section{Introduction}

Biological rhythms are an integral part of the daily lifecycle of all living organisms. They are endogenously generated by biological clocks, and are characterised by their innate period lengths $(\tau)$. Biological clocks are self-sustained and temperature compensated, however they synchronise to cyclic external cues (Brady, 1979). In the absence of entraining cues the rhythms free-run at their inherent period lengths. Biological rhythms allow animals to anticipate predictable changes in the environment so as to adjust their physiology and behaviour accordingly.

Circadian rhythms are biological rhythms with periods of approximately 24 hours, and the physiology and behaviour of an animal is commonly organised around the 24 hour day. Photoperiod is the most frequently used cue to which the circadian clock entrains (Pittendrigh and Minis, 1964; Benstaali et al., 2001).

Locomotor activity patterns regularly exhibit a 24 hour rhythm with animals regulating their activity to the time of the day that will optimise their survival. Small desert dwelling mammals have a large surface area to volume ratio and are therefore prone to desiccation and have to regulate both their energy and water balance tightly (Macfarlane, 1968).

Aboveground activity is thus inhibited in these small mammals and their locomotor activity is mostly concentrated during the dark phase of the diel cycle when temperatures are more equable and water balance can be regulated. A nocturnal lifestyle would also assist in the avoidance of a number of diurnal predators (Demas et al., 2001).

The genus Acomys comprises a number of species which occur in a variety of habitats ranging from forest to dry hot desert areas. It appears that the locomotor activity of three species have previously been investigated, the common spiny mouse (A. cahirinus), the golden spiny mouse (A. russatus) and the African spiny mouse (A. spinosissimus). The common and African spiny mice have been shown to be strictly nocturnal (Hoole et al., 2012; Weber and Hohn, 2005), whereas the golden spiny mouse appears to be diurnal in its natural habitat (Cohen and Kronfeld-Schor, 2006). The diurnal activity pattern of the golden spiny mouse has been ascribed to competitive exclusion and thermoregulatory considerations and intra-specific activity rhythms are much more variable than in the other species (Cohen and Kronfeld-Schor, 2006; Hoole et al., 2012; Weber and Hohn, 2005). 
The Arabian spiny mouse (A. dimidiatus) is a social, omnivorous rodent that has a wide distribution in south-western Asia and north-eastern Africa. It occurs in semi-arid to dry habitats in rocky areas and deciduous forests (Harrison \& Bates, 1991). The Arabian spiny mouse has long been regarded as a subspecies of the common spiny mouse however, recent genetic analysis revealed sharply different karyotypes that separate them into different species (Volobouev et al. 2007).

This study was undertaken to characterise the activity distribution of the Arabian spiny mouse throughout the $24 \mathrm{~h}$ day and assess the endogenous circadian rhythm under constant darkness and determine the period length. Additionally, we evaluated the effect of ambient temperature to investigate whether the level of activity would remain constant, and whether changes in day length would have an effect on the daily activity rhythm.

\section{Material and methods}

\section{General}

The experimental animals used in this study consisted of ten spiny mice, 4 males and 6 females (body mass, mean $\pm \mathrm{SD}: 57.1 \pm 7.9 \mathrm{~g}$ ). All spiny mice were adult, none appeared to be old. The spiny mice were collected at Raydah protected area near Abha city in south western Saudi Arabia $\left(18^{\circ} 00^{\prime} \mathrm{N}, 2^{\circ} 46^{\prime} \mathrm{E}\right)$. The mice were trapped with cage live traps (Strauss et al., 2008) baited with bread and peanut butter. After capture, the animals were transported to the animal facility at the Department of Zoology, College of Science, King Saud University, Riyadh, Saudi Arabia where the experimental procedures were carried out. The experimental protocol was evaluated by the Animal Use and Care of the University of Pretoria, ethics clearance number EC015-12.

The mice were housed individually in polyurethane terraria $(50 \times 40 \times 40 \mathrm{~cm})$ and provided with wood shavings, a nest box and tissue paper as nesting material. Food and water was provided ad libitum, and a few drops of multivitamins were added to the drinking water. Animals were fed on pelleted poultry food from the Arabian Agricultural Services Company (Arasco, Riyadh, Saudi Arabia) every 14 days at the end of the cycle. During the feeding times the general health and condition of the animals was monitored. The experimental room was temperature controlled at $25 \pm 1{ }^{\circ} \mathrm{C}$ and the room was light controlled which enabled us to create different light regimes for the experimental period. Animals were in the laboratory for several months prior to commencement of experiments. 


\section{Experimental procedures}

Animals were maintained on a 12L:12D cycle (6:00 - 18:00L) for 14 days to determine how well they entrain to light cycles. This was followed by a 14 day DD cycle in order to determine the period of endogenous free running rhythms of locomotor activity $(\tau)$ of spiny mice. Subsequently the lights were switched back to the original 12L:12D cycle to re-entrain the animals, after which the light cycle was inversed to investigate whether and how fast the animals change their activity according to the new light cycle.

Subsequently, animals were returned to a LD light cycle and temperature was changed every 14 days. Temperature regimes were in the following sequence: $25^{\circ} \mathrm{C}, 30^{\circ} \mathrm{C}, 20^{\circ} \mathrm{C}$ and $35^{\circ} \mathrm{C}$.

Next the spiny mice were subjected to light cycles of different lengths at an ambient temperature of $25^{\circ} \mathrm{C}$. First animals were acclimated to a 12L:12D light cycle for a week, following a two week period of $8 \mathrm{~L}: 16 \mathrm{D}$ simulating a short day, and a two week period of 16L:8D simulating a long day.

\section{Activity measurements}

An infrared captor (Quest PIR internal passive infrared detector; Elite security products (ESP), Electronic lines, UK) was fitted above each of the cages in which the animal was housed. These sensors were placed in the middle of each cage to detect any movement that the animal made in any area of the cage. A reading was taking once every minute and the activity measurements were captured by the program Vital View on a computer system (Vital View $^{\mathrm{TM}}$, Minimitter Co., Inc., Sunriver, OR, USA; www.minimitter.com).

\section{Data analyses}

Activity was depicted as double plotted actograms with Actiview Biological Rhythm Analyses 1.2 software (Minimitter Co., Inc., Sunriver, OR, USA; www.minimitter.com) to visualise activity patterns. Clocklab was used for all activity analyses (ClockLab TM, Actimetrics, Evanston, Il. U.S.A.). To determine statistical differences between different light cycles, Statistica 10.0 (C StatSoft, Inc. 1984-2011) was employed. Due to small sample sizes, non-parametric statistics were used for all calculations.

\section{Results}

$12 L: 12 D$

All ten spiny mice displayed entrainment of their locomotor activity to a $12 \mathrm{~L}: 12 \mathrm{D}$ light cycle. All individuals were active during the scotophase of the light cycle $(n=10$, mean $=94.2 \pm$ 
1.6\%), 6 animals were active continuously, while 4 animals showed two distinct bouts of activity, one of these animals exhibited a small bout of activity during the photophase. The peak activity time occurred almost five hours after onset of the dark phase $(n=10$, mean $=$ $22 \mathrm{~h} 47 \pm 0 \mathrm{~h} 33)$.

Seven animals displayed clear onsets but not offsets, two animals exhibited distinct on and offsets while one individual displayed a distinct offset but no discernible onset. The mean phase angle for the onsets was $18 \mathrm{~h} 19 \pm 0 \mathrm{~h} 04$ while the mean phase angle for offsets was $5 \mathrm{~h} 53 \pm 0 \mathrm{~h} 35$ (Figure 1). The activity peaked at 22h47 $\pm 0 \mathrm{~h} 33$.

$D D$

All ten spiny mice showed circadian rhythmicity, one mouse had a rhythm longer than 24 hours, while all the others were shorter than $24 \mathrm{~h}$ hours. The mean period was $23 \mathrm{~h} 49 \pm 0 \mathrm{~h} 04$, $(\mathrm{n}=10$, range $23 \mathrm{~h} 36-24 \mathrm{~h} 06)$. The mean percentage of activity during the subjective night was $84.6 \pm 1.7 \%$, which is a significant decrease in nocturnal activity compared to the first LD cycle (Wilcoxon matched paired test $\mathrm{n}=10 ; p=0.005$ ) (Figure 2). The mean activity time (alpha, a) was $11 \mathrm{~h} 47 \pm 0 \mathrm{~h} 32$.

\section{L:12D and inversed $L D(12 D: 12 L)$}

All spiny mice inverted their activity when the light and dark phases were inversed. After inverting the light cycles, re-entrainment of the onset of activity to the new cycle took place relatively quickly however, a masking effect was present and full entrainment of the activity rhythm varied between 4 and 11 days, with a mean time of 8.8 days. The mean percentage of activity during the dark phase of DL was calculated once re-entrainment was completed, and presented as $88.4 \pm 2.2 \%$. The percentage of activity displayed during the dark phases of LD2 and DL was not significantly different (91.9 vs 88.4\%) from one another (Wilcoxon matched paired test $\mathrm{n}=10, Z=1.37 ; T=14 ; p=0.17$ )(Fig 3).There was no significant difference in the percentage of activity during the dark phase of LD1 and LD2 in the spiny mouse (Wilcoxon matched paired test $\mathrm{n}=10, Z=1.27 ; T=15 ; p=0.20)$. Nine animals presented a peak of activity shortly after onset of darkness ( $\mathrm{n}=9,6 \mathrm{~h} 48 \pm 0 \mathrm{~h} 06)$, activity of the other animal peaked shortly before onset of the light phase. 
Figure 1: An example of a double plotted actogram of a well-entrained locomotor activity rhythm of an Arabian spiny mouse during a LD cycle, showing a distinct onset and a less well defined offset of activity. The bar at the top of the actogram illustrates light and dark phases while the lines on the Y-axis are consecutive days. For more examples, see appendix A.

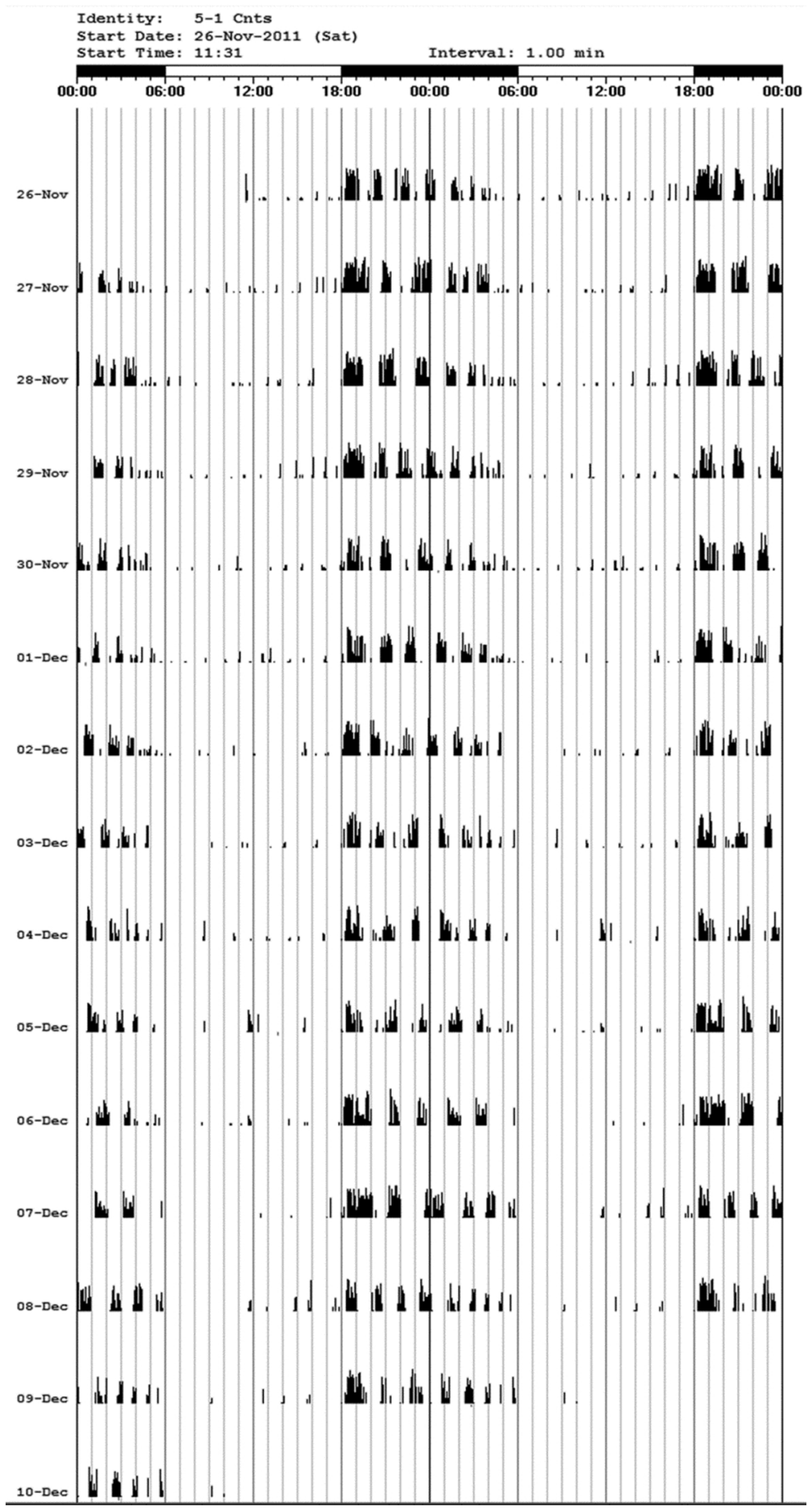


Figure 2: An example of a spiny mouse during DD with a free-running period slightly shorter than 24h, (inset) periodogram of the same actogram showing the period at $23.58 \mathrm{~h}$. The bar at the top of the actogram illustrates the constant dark phase while the lines on the $\mathrm{Y}$-axis are consecutive days.

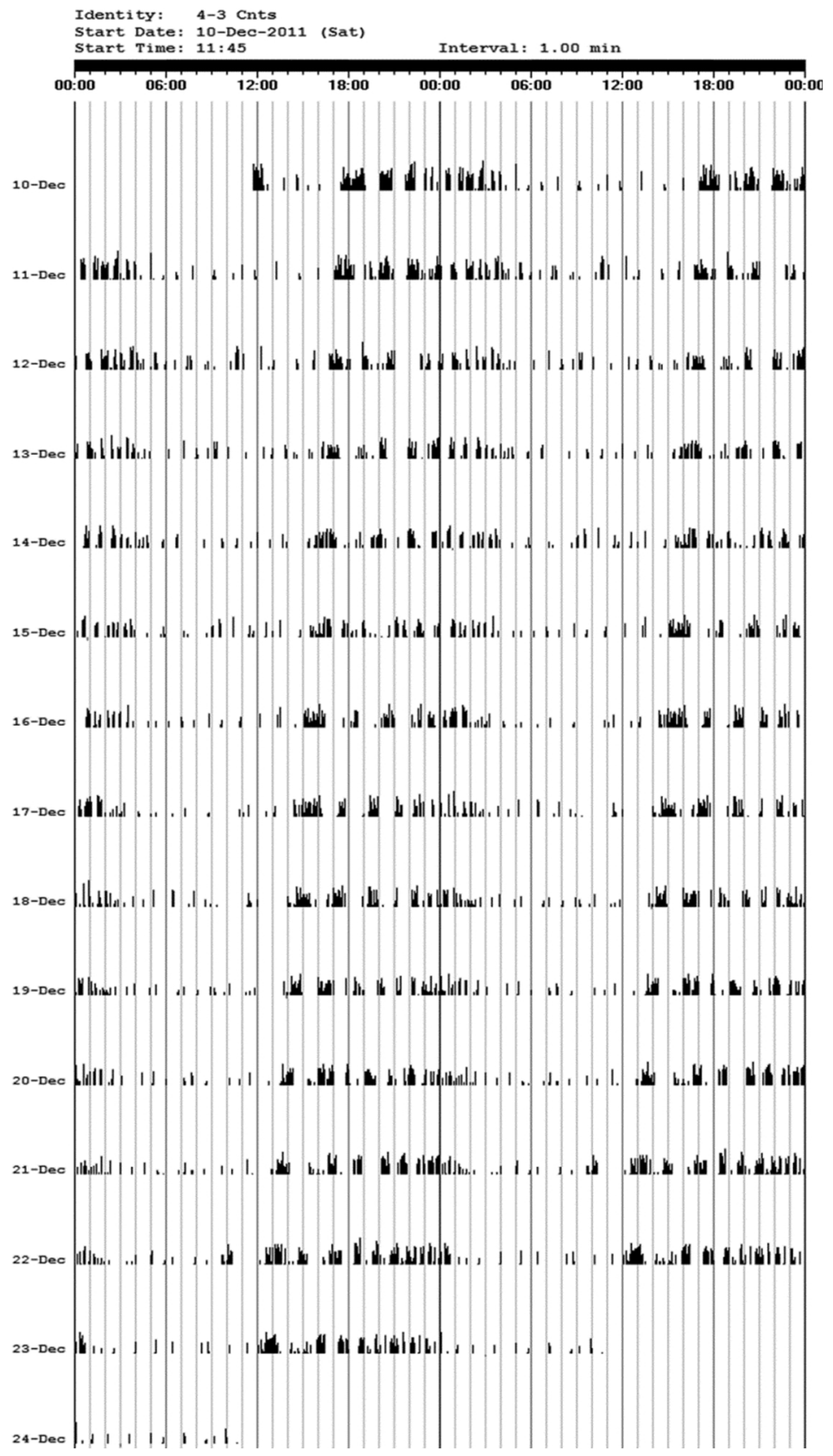


Figure 3: An actogram showing the activity of a spiny mouse at the transition between LD and DL. Masking of activity is clearly visible as is the long re-entrainment time. The inversion of the lights took place on the $7^{\text {th }}$ of January. The bar at the top and the middle of the actogram illustrates light and dark phases while the lines on the Y-axis are consecutive days.

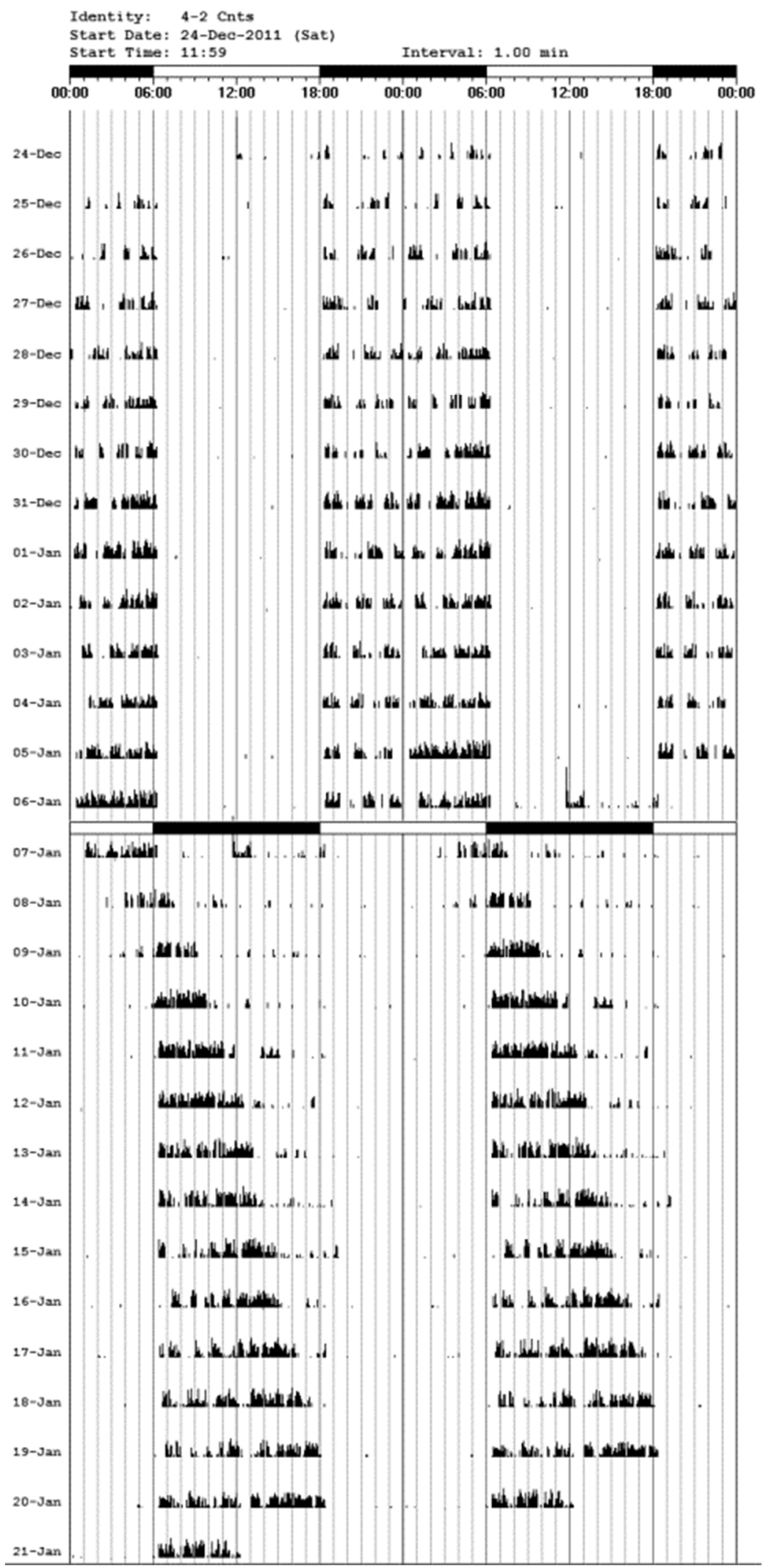


Temperature variation on a 12L:12D light cycle

All animals maintained nocturnal activity patterns during all four of the temperature variations. The mean percentage of activity during the night did not differ significantly between the different ambient temperature periods (Friedman's two way analysis, $p=0.145$ ). Also the total counts per day did not differ significantly between the various ambient temperature cycles (Friedman's two way analysis, $\mathrm{p}=0.266$ ).

Long (16L:8D) and short (8L:16D) days

One spiny mouse died during the experiment, thus $n=9$ for this part. All nine spiny mice exhibited more than $80 \%$ activity during the dark phase of the 12L:12D light cycle $(n=9$, mean $=90.4 \pm 1.5 \%$ ). When the dark component of the day was lengthened to $8 \mathrm{~L}: 16 \mathrm{D}$, the mean percentage of activity during the dark increased to $96.0 \pm 0.8 \%(n=9)$, while the dark phase length was decreased to $16 \mathrm{~L}: 8 \mathrm{D}$ there was a decrease in night time activity $(n=9$, mean $78.29 \pm 2.52 \%$ ). The different lengths of activity in the three light phases were significantly different from one another (Friedman's two way analysis, $p<0.001$ ). A power failure at the end of the short day cycle prohibited us from observing whether the lengthening of activity was immediate or not.

The mean time activity $(\alpha)$ is $12 \mathrm{~h} 28 \pm 0 \mathrm{~h} 18$, and activity of seven out of the nine mice peaked around one hour after onset of darkness $(\mathrm{n}=7,19 \mathrm{~h} 04 \pm 0 \mathrm{~h} 03)$, while the other two showed peak activity shortly before onset of the lights . During a short day photoperiod, the mean $\alpha$ during the night is expanded along with the longer night to $16 \mathrm{~h} 36 \pm 0 \mathrm{~h} 23$. The mean peak of activity of seven animals was $21 \mathrm{~h} 38 \pm 0 \mathrm{~h} 03$, while activity of the other two animals peaked just before the end of the dark period. The mean $\alpha$ for activity decreased when the night was shortened $($ mean $=9 \mathrm{~h} 16 \pm 0 \mathrm{~h} 30)$. The mean peak of activity of eight animals was $17 \mathrm{~h} 23 \pm$ 0h07, and activity of the remaining animal peaked closely before onset of the light period. Mean $\alpha$ for the three light cycles was significantly different from each another (Friedman's two way analysis, p<0.001) (Fig. 4). 
Figure 4: A double plotted actogram of a spiny mouse illustrating the difference in $\alpha$ during long and short day light cycles. The bar at the top and the middle of the actogram illustrates light and dark phases while the lines on the $\mathrm{Y}$-axis are consecutive days.

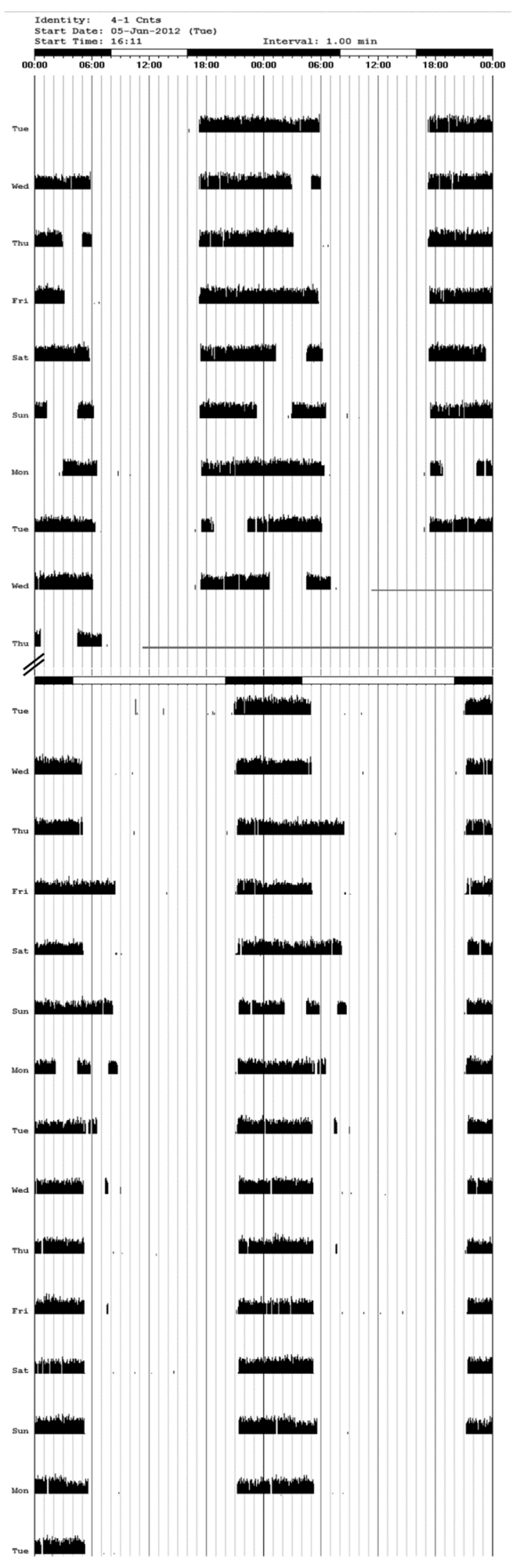




\section{Discussion}

Activity patterns may change in response to varying environmental conditions as well as seasonal fluctuations (Hoogenboom et al., 1984). However, under controlled laboratory conditions rhythms can be investigated under specific lighting schedules or constant conditions. Solitary housing of social species is not ideal, yet in order to record activity of single animals it is necessary in some instances. Previous studies have shown that individual housing of social species may lead to reduced activity and other types of adverse behaviours (Hurst et al. 1997), however we presumed that the proportion of activity during night and day would remain similar even if the amplitude of activity was reduced, hence it would not implicate negatively on the circadian behaviour.

The Arabian spiny mouse has a wide geographical range in Saudi Arabia (Bates 1994, Harrison \& Bates, 1992), in some areas the day temperatures in wadi's (desert valleys) can reach up to $45^{\circ} \mathrm{C}$ while night temperatures drop to $4^{\circ} \mathrm{C}$ (Al-Helal, 2003). In the laboratory at an ambient temperature of $25^{\circ} \mathrm{C}$, the Arabian spiny mouse appears to restrict its activity to being entirely nocturnal. It entrains its daily locomotor activity to commence after the transition from light to dark and ceases activity before the next LD cycle. Very little activity was observed during the light phase of the LD cycle. All mice were captured during the night, indicating that Arabian spiny mice are nocturnal in their natural environment as well. Findings of this study are similar to that observed in the common spiny mouse (Weber and Hohn, 2005) as well as both the African and Cape spiny mice (Hoole et al., 2012; Powell et al., 1981). The predominantly nocturnal activity pattern has also been demonstrated in a number of heterospecific jirds and gerbils that occur sympatrically with the Arabian spiny mouse, intimating that activity at night is an important strategy for survival in this harsh and inhospitable environment (Alagaili et al., 2012; Alagaili et al., 2013). In contrast, the golden spiny mouse also occurs in desert habitats but shows less distinct activity patterns. When maintained alone in the laboratory it shows mainly nocturnal behaviour however, in its natural environment, as well as in captivity with the common spiny mice in close proximity, it displays a diurnal activity pattern. The diurnal activity has been ascribed to competitive exclusion and thermoregulatory requirements (Friedman et al., 1997; Cohen et al., 2009). Arabian spiny mice show very distinct onsets of activity with marked activity shortly after the onset. Activity offsets were not as clear cut implying that the most important entraining agent is the transition period from light to dark. A duel oscillator system has been proposed to explain differential responses to onsets and offsets of activity in rodents (Daan et al. 2001), in 
this case the well-defined onsets suggest that the E (evening) oscillator has a stronger link to locomotor activity than the $\mathrm{M}$ (morning) oscillator.

When maintained under constant darkness all of the spiny mice exhibited an endogenous rhythm of locomotor activity that drifted slightly relative to solar time. Most of the mice exhibited free running rhythms shorter than 24 hours. The length of the free-running period does not seem to have any specific relevance since the free-running period of rodents has been shown to be a plastic property and can be influenced by environmental and experimental conditions (Aschoff, 1979; Weber and Hohn, 2005; Weisgerber et al., 1997).

Arabian spiny mice revealed an immediate response in the onset of their activity to an inverse in the light cycle. A masking effect of activity is clearly visible during the light phase of the DL cycle, emphasizing that these animals are strictly nocturnal. The offset shifted much more slowly such that the activity was only really fully entrained after about eleven days. A similar pattern of onset and offset was observed in the southern African spiny mouse, $A$. spinosissimus (Hoole et al., 2012). Interestingly, re-entrainment experiments conducted on the common spiny mouse, $A$. cahirinus indicated an immediate phase shift in both the onset and offsets of activity (Cohen et al., 2009). The offsets of activity in the Arabian spiny mouse appear to be more defined, the longer the mice are maintained under the experimental set up. The rate of re-entrainment depends on a number of internal and external factors such as the strength of the zeitgeber, the period and phase response curve of the pacemaker and experimental protocol (Aschoff et al., 1975, Pittendrigh and Daan, 1976), which renders it challenging to compare between different studies and species.

The Arabian spiny mouse responded to a change in photoperiod exerted on it under laboratory conditions, under a short day $8 \mathrm{~L}: 16 \mathrm{D}$ the amount of activity restricted to the dark period peaked at around $96 \%$ of all activity, whereas under a long day, $16 \mathrm{~L}: 8 \mathrm{D}$ the activity devoted to the dark period dropped to $78.2 \%$ with more activity occurring in the light phase than on a short day. For a strictly nocturnal rodent, one would expect similar amounts of activity during each of the light phases such that the activity period expands or contracts along with longer and shorter dark periods. Considering the extended time these animals require to re-entrain after a light phase reversal, it is possible that two weeks may not be sufficient to fully adjust activity patterns to altered day lengths.

Variations in ambient temperature does not change the amplitude of activity of the Arabian spiny mouse when maintained on a 12L:12D light cycle. The temperature range was 
potentially not large enough to observe a change in behaviour. In addition, these experimental conditions were fairly robust as the temperature was constant during the light and dark phases of the light cycle. Activity profiles may be expected to show a change when exposed to different light and dark temperature variations.

The ancestral state of locomotor activity in mammals has been suggested to have been nocturnal (Smale et al., 2003) with the circadian system of most nocturnal mammals being very uniform, but diurnality has evolved in some animals over evolutionary time but only in a proportionally few small mammal species (Smale et al., 2003; Johnson et al., 2003). In the case of small mammals moving into arid environments this pattern of activity has been generally maintained in the desert dwelling jirds and gerbils (Demas et al., 2001). The various species of Acomys currently present in the Middle East have speciated from an ancestral stock that migrated from the savannas of tropical Africa (Denys et al., 1994). This study presents the first description of locomotor activity patterns in the Arabian spiny mouse which, like other small desert mammals displays a predominantly nocturnal activity pattern. The activity rhythm free-runs in the absence of external cues and re-entrains in response to an inversed light cycle. During re-entrainment, activity is masked during the light phase, the offset of activity shifts gradually until fully entrained after about 11 days. Different ambient temperatures do not alter the amplitude of locomotor behaviour; however, a more refined experimental setup may render more distinct results. The day length changes the amount of activity displayed during the dark phase but, this may be related to the long reentrainment time of these animals and activity may stabilise after some time on a light cycle.

\section{Acknowledgements}

We certify that experiments were carried out in accordance with the National Institute of Health Guide for the Care and Use of Laboratory Animals. Ethics clearance was obtained from the ethics committee of the University of Pretoria (EC015-12). We extend our appreciation to the Deanship of Scientific Research at the King Saud University for funding the work through the research group project No. RGP_VPP_020. We thank HH Prince Bandar Bin Mohammed Bin Saud, President, Saudi Wildlife Authority for permission to trap the animals in the Raydah Protected Area in south western Saudi Arabia. NCB gratefully acknowledges support from the Visiting Professors Programme of King Saud University to undertake research in Saudi Arabia. 


\section{References}

Alagaili, A.N., Mohammed, O.B., Bennett, N.C., Oosthuizen, M.K., 2012. Lights out let's move about: locomotor activity patterns of Wagner's gerbil, (Gerbillus dasyurus) from the desert of Saudi Arabia. Afr. Zool.47(2), 195-202.

Alagaili, A.N., Mohammed, O.B., Bennett, N.C., Oosthuizen, M.K., 2013. A tale of two jirds: locomotor activity patterns of the King jird and the Lybian jird from the Arabian Peninsula. J. Arid Environ. 88,102-112.

Al-Helal, I.M., 2003. Environmental control for poultry buildings in Riyadh area of Saudi Arabia. J. Saudi Soc. Agric. Sci. 16, 87-102.

Aschoff, J., Hoffmann, K., Pohl, H., Wever, R., 1975. Re-entrainment of circadian rhythms after phase-shifts of the zeitgeber. Chronobiol. 2, 23-78.

Aschoff, J., 1979. Circadian rhythms: influences of internal and external factors on the period measured in constant conditions. Z. Tierphysiol. 49,225-249.

Bates, P.J.J., 1994. The distribution of Acomys (Rodentia: Muridae) in Africa and Asia. Isr.J.Zool. 40, 199-214.

Benstaali, C., Mailloux, A., Bogdan, A., Auzeby, A., Toutoui, Y., 2001. Circadian rhythms of body temperature and motor activity in rodents. Their relationships with the light-dark cycle. Life Sci. 68, 2645-2656.

Brady, J., 1979. Biological Clocks. Edward Arnold Publishers. London.

Cohen, R., Kronfeld-Schor, N., 2006. Individual variability and photic entrainment of circadian rhythms in golden spiny mice. Physiol.Behav. 87,563-574.

Cohen, R., Smale, L., Kronfeld-Schor, N., 2009. Plasticity of circadian activity and body temperature rhythms in golden spiny mice. Chronobiol. Int. 26, 430-446.

Daan, S., Albrecht, U., Van der Horst, G.T.J., Illnerová, H., Roenneberg, T., Wehr, T.A.,Schwartz, W.J., 2001. Assembling a clock for all seasons: Are there M and E oscillators in the genes? J.Biol.Rhythms 16, 105-116.

Demas, G.E., El-Bakry, H.A., Mintz, E.M., Zahari, W.M., Bartness, T.J., 2001. Wheelrunning activity patterns of five species of desert rodents. Biol. Rhythms Res. 32, 1-16.

Denys, C., Gautun, J.C., Tranier, M.,Volobouev, V., 1994. Systematics of the spiny mice (Acomys: Muroidae): molecular and biochemical patterns. Isr. J. Zool. 40, 215-246. 
Friedman, D., A. Haim, and N. Zisapel. 1997. Temporal segregation in coexisting spiny mice (Genus Acomys): role of photoperiod and heterospecific odour. Physiol. Behav. 62, 407-411. Harrison, D.L., Bates, P.J.J., 1991. The Mammals of Arabia. $2^{\text {nd }}$ Edition. Harrison Zoological Museum Publications. Sevenoaks, UK.

Hoogenboom, I., Daan, S., Dallinga, J.H., Schoenmakers, M., 1984. Seasonal change in the daily timing of behaviour of the common vole, Microtus arvalis. Oecologia 61, 18-31.

Hoole, C., Oosthuizen, M.K., Chimimba, C.T., Bennett, N.C., 2012. Locomotory activity rhythm in the spiny mouse, Acomys spinosissimus from southern Africa: light entrainment and endogenous circadian rhythms. J. Zool. Lond. 288, 93-102.

Hurst, J.L., Barnard, C.J., Nevison, C.M., West, C.D., 1997. Housing and welfare in Laboratory rats: Welfare implications of isolation and social contact among caged males. Animal Welfare 6, 329-347.

Johnson, C.H., Elliott, J., Foster, R., Honma, K., Kronauer, R., 2003. Fundamental properties of circadian rhythms. (Chapter 3). In Chronobiology: biological timekeeping (J. C. Dunlap, J. J Loros, P. J. DeCoursey, eds.), Sinauer Associates, Sanderland, MA. Pp. 67-105.

Macfarlane, W.V., 1968. Adaptation of ruminants to tropics and deserts. In Adaptation of domestic animals (E.S.E. Hafez ed.) Lea and Febiger. Philadelphia, Pennsylvania. Pp 164182.

Pittendrigh C.S., Minis, D.H., 1964. The entrainment of circadian oscillations by light ad their role as photoperiodic clocks. Am.Nat. 98, 261-294.

Pittendrigh, C.S., Daan, S., 1976. A functional analysis of circadian pacemakers in nocturnal rodents. VI. Entrainment: Pacemaker as a clock. J. Comp. Physiol. 106, 291-331.

Powell, J.A., Belitsky, D.W., Rathbun, G.B., 1981. Demography and activity patterns of some small mammals from the Cape province, South Africa. J. Mammal. 62, 646-649.

Smale, L., Lee, T., Nunez, A.A., 2003. Mammalian diurnality: some facts and gaps. J. Biol. Rhythms 18, 356-366.

Strauss, M., Sher Shah, M., Shobrak, M., 2008. Rodent trapping in Saja/Umm Ar-Rimth protected area of Saudi Arabia using two different trap types. Zool. Middle East 43, 31-39. 
Volobouev, B., Auffray, J.C., Debat, V., Denys, C., Gautun, J.C., Tranier, M., 2007. Species delimitation in the Acomys cahirinus-dimidiatus complex (Rodentia, Muridae) inferred from chromosomal and morphological analyses. Biol.J.Linn.Soc. 91, 203-214.

Weber, E.T., Hohn, V.M., 2005. Circadian activity of the spiny mouse, Acomys cahirinus. Physiol. Behav. 86, 427-433.

Weisgerber, D., Redlin, U., Mrosovsky, N., 1997. Lenthening of circadian period in hamsters by novelty-inducing wheel running. Physiol. Behav. 62,759-765. 